\title{
Assessing the Applicability of Three Approaches to Design-Oriented Research
}

\author{
Jing Zhou1, 2*, Christopher Kueh², Yi Lin'1 \\ ${ }^{1}$ College of Communication and Art Design, University of Shanghai for Science and Technology (USST), Shanghai 200093, \\ China \\ ${ }^{2}$ School of Arts and Humanities, Edith Cowan University (ECU), Australia \\ *Corresponding author: Jing Zhou, jzhou9@our.ecu.edu.au
}

\begin{abstract}
The three main approaches in inquisitive research design are qualitative, quantitative, and mixed methods ${ }^{[1]}$. However, recent developments in the research field have resulted in multiple other approaches, borrowing ideas from a broad range of fields. One such approach is the practice-led approach. This approach involves an efficient design process, novel qualitative interviewing methods, together with data mining procedures from quantitative data collection ${ }^{[2]}$. This paper assesses the practice-led approach used in user experience (UX) design, together with three approaches: co-design, service design, and reflective practice.
\end{abstract}

Keywords: Practice-led approach; Design approaches; User experience

Publication date: August 2021; Online publication: August 30, 2021

\section{Introduction}

The practice-led approach allows a researcher to integrate creative practice as well as innovative outputs and methods into the research design to ensure that the study under consideration is effectively conducted. However, instead of collecting data, this approach creates the data that are then to be collected ${ }^{[2]}$. This article introduces the creation of data through collaboration, observation, and reflection on a design project. Three similar innovative approaches will be investigated and one or a combination of approaches will be selected for the use in design-project.

\section{Three practice-led approaches}

Co-design, service design, and reflective practice are the three approaches that will be analyzed and discussed. These three approaches have been dominantly used in UX design. However, it is vital to take note of their subtle differences that enhance their suitability to specific research.

\subsection{Co-design}

Co-design was initially referred to as co-operative design. This is an approach that focuses its ideologies on research design procedures. Co-design has been extensively applied in software design industry to ensure that the resulting product or service created is responsive to the specific practical needs of a user.

Co-design can create data visually and inclusively. One main advantage of co-design is its utilization of participants in the design workshop. Through numerous participants with various backgrounds and roles in the successful implementation of a project, this research approach provides quality information that is actionable in the field of its application. In the research paper titled "Co-design with People Living with 
Cognitive or Sensory Impairments," Hendriks and other researchers utilized the inputs of 42 participants who have worked with people who have autism spectrum disorder, aphasia, dementia, visual and auditory impairments, and other special needs groups ${ }^{[3]}$. This advantage can also be witnessed in the research by Villalba and other researchers in $2019^{[4]}$. They utilized flashcards that have been designed to prompt discussion and aid in exploring the experiences of the participants. Other than that, sketches and drawings are dominantly used in this approach to help participants express themselves adequately.

Co-design involves flexible methods. Multiple co-design methods have been applied to research affording the approach flexibility. Experience-based design, co-design workshop, the Double Diamond design process are some of the techniques under this research design approach. A wealth of methods provides an avenue for fine-tuning a research approach to suit every need of research. These methods also allow for integration within and beyond the practice-led approach. Therefore, a researcher can fine-tune their methodology to harness the specific strengths while avoiding weaknesses that would curtail the quality of insights obtained.

Co-design may discourage uniform decision-making, resulting in poor quality insights. This is one of the main limitations of the approach. Participants will, more often than not, disagree over the importance of multiple variables, features, and ideas central to the service or product in question. In Page's paper regarding co-design, in the context of design management, he elucidated this limitation ${ }^{[5]}$. He also mentioned that conflict, as an ever-present limitation, curtails the ability of the focus group to conclusively agree on various aspects. Furthermore, a failure to identify with the data collection process as co-creators also hinders the quality of insights obtained. According to Bowen and other researchers, a lack of sense of ownership can limit the quality and exhaustiveness of the insights provided by the participants of a study [6].

\subsection{Service design}

Service design is a multistep process that harnesses the innovative abilities of creativity through iteration in the design of services. The first step is usually an exploration of customers' experiences and, consequently, the generation of new service alternatives that can be converted to models, tested, and then implemented.

Service design can be a problem-solving activity, thus creating value. Design can either be viewed through the lens of problem-solving or exploratory inquiry. The critical concept of service design is founded on the utilization of a rational problem-solving perspective. In a study titled "Prototyping in Service Design," prototypes were used as external representations of problems, helping them to think and arrive at desired solutions ${ }^{[7]}$. Lastly, service walkthrough, a technique under service design was employed in a paper titled "Examining the Service Walkthrough Technique" to showcase prototypes while allowing more detailed insights and feedbacks from participants ${ }^{[8]}$. The use of prototypes admits that an ideal goal or state is being pursued. The value created thus results from creating an ideal product that serves the desires, goals, and needs of users ${ }^{[9]}$. The research workshop run will involve potential customers. Hence if designed well, the service solutions reached can pique the interest of potential customers to the service.

Service design can present a design prototype for all audiences. Prototypes provide a platform to showcase the need for a service, hence making it easier to convince sponsors, developer organizations, management, and other relevant stakeholders [7]. In a study titled "Reaching into Patients' Homes Participatory Designed AAL Services," the researchers quoted the significant participation of patients, physicians, and caregivers. These stakeholders are the ones that would benefit the most from its implementation.

Service design may consume considerable resources yet poses a high risk for obsolesce. Once the prototype has been made, the next step involving users could result in the obsolesce of the prototype. This 
can occur if users find that the prototype does not serve their interests. The design process usually requires at least two runs to offer multiple chances of reviewing the prototype. This results in a considerable amount of time, human resources, and financial investments. Due to its iterative nature, making changes that require alterations to the core ideas of the service can consume a lot of resources. Junginger and Sangiorgi, through their paper "Service Design and Organizational Change," observed that changing the core precepts of service requires a guarantee of thoroughness in the service design inquiry process ${ }^{[10]}$.

\subsection{Reflective practice}

Reflective practice incorporates conceptual lenses, which provide clear and sequential instructions, for the documentation of reflections and their utilization as a source of data. Reflective practice has been applied in various fields. Reflective practice has been defined as a skill that draws upon past experiences, and then utilizes a theory-guided approach that provides an avenue to inquire and obtain insights about past experiences.

The role of intuition in reflective practice is evident. However, developing supplementary materials to guide the utilization of information obtained from intuitions and emotions to produce meaningful conclusions is a more significant hurdle in this approach ${ }^{[11]}$. As a consequence, evaluation is required to ensure that the approach would yield useful and actionable data. The evaluation process focuses on similar aspects as the co-design approach; that is, the quality of the produced output, the created service utility for users, and the overall perspective change that the service has generated among its targeted population.

Reflective practice can improve decision-making and problem-solving capacities. In a research paper titled "Overtraining and the Complexities of Coaches' Decision-Making," the researchers argued that the use of reflective practice by coaches would help to improve the quality of decisions made in regard to the athletes they are in charge of ${ }^{[12]}$. Through intuition and unique insights garnered from their experience in the field, coaches have successfully improved the accuracy of their decisions and are in a pole position to solve the problems that athletes encounter. Furthermore, reflectively critiquing their decisions results in better cognitive creativity ${ }^{[13]}$.

In another study, “Assessing Reflective Practice in Solving Design Problems," it has been observed that reflection is a crucial factor when solving any problems. The utilization of a reflection-based approach accumulates adequate weight in design processes; in this case, the design of a questionnaire to explore reflection ${ }^{[14]}$. Hong and Choi further noted that the ability of the reflective practice to instigate selfawareness significantly improves the quality of insights obtained ${ }^{[14]}$. This is the main advantage of reflective practice.

The documenting of reflective practice can transform thinking into published outcomes in the broader community. In a paper titled "Institutionalizing a Broader View of Scholarship Through Boyer's Four Domains," the authors asserted that their study plays a significant role in the solution of a community problem. Through creative, reflective practice, the study was designed to utilize insights from the community to redefine various aspects of the scholarship domain ${ }^{[15]}$.

Reflective practice may have time constraints. An interview-based reflective study on reflective practice showed that the main limitation of the faculty members, who applied the approach to their teaching methods, was time. The study, "Examining Faculty Reflective Service," also uncovered other constraints associated with the approach, such as individual biases and faculty motivation ${ }^{[16]}$. Just like reflective practice, minimizing the amount of time it requires to conduct research using research methods is a complex process, which involves the incorporation of ideas and methods from other approaches. 


\section{Conclusion}

Through research, the three practice-led research methodologies discussed above have been subjected to scrutiny to determine their strengths and weaknesses. Through the use of practical examples of research designs, the findings are as follows: (1) Co-design is efficient in the first stage of idea generation and creation of visual data; (2) Service design is best suited for problem-solving in a design project; however, at times, it needs the incorporation of a collaborative approach to ease its time and financial requirements; (3) Reflective practice can significantly aid problem-solving since it instigates self-awareness; (4) Both, service design and reflective practice, have significant time input as their most significant limitation for use in the design-project.

\section{Disclosure statement}

The authors declare that there is no conflict of interest.

\section{References}

[1] Creswell JW, 2003, Research Design: Qualitative, Quantitative, and Mixed Methods Approaches (2nd ed.), Sage Publications Inc., Thousand Oaks, California, 5.

[2] Nicolini D, 2016, Knowing in Organizations: A Practice-Based Approach, M.E. Sharpe, Inc., New York.

[3] Hendriks N, Slegers K, Duysburgh P, 2015, Codesign with People Living with Cognitive or Sensory Impairments: A Case for Method Stories and Uniqueness. CoDesign, 11(1): 70-82. https://doi.org/10.1080/15710882.2015.1020316

[4] Villalba C, Jaiprakash A, Donovan J, et al., 2019, Testing Literature-Based Health Experience Insight Cards in a Healthcare Service Co-Design Workshop. CoDesign, : 1-13. https://doi.org/10.1080/15710882.2018.1563617

[5] Page T, 2018, Co-Design in the Context of Design Management. i-Manager's Journal on Management, 13(2): 1 .

[6] Bowen S, McSeveny K, Lockley E, et al., 2013, How Was It for You? Experiences of Participatory Design in the UK Health Service. CoDesign, 9(4): 230-46. https://doi.org/1 $0.1080 / 15710882.2013 .846384$

[7] Blomkvist J, 2014, Representing Future Situations of Service: Prototyping in Service Design. Linköping University Electronic Press.

[8] Blomkvist J, Arvola M, 2014, The 28th International BCS Human-Computer Interaction (HCI 2014) Conference, September 9-12, 2014: Pausing or Not?: Examining the Service Walkthrough Technique. British Computer Society (BCS), Southport, UK, 171-6. https://doi.org/10.14236/ewic/hci2014.18

[9] Wetter-Edman K, 2010, The Concept of Value in Design Practice - An Interview Study. 2nd Nordic Conference on Service Design and Service Innovation, Linko“ping, Sweden.

[10] Junginger S, Sangiorgi D, 2009, Service Design and Organizational Change: Bridging the Gap Between Rigor and Relevance. International Association of Societies of Design Research, Seoul, Korea, 4339-48.

[11] Hsu YC, Ching YH, 2013, Mobile App Design for Teaching and Learning: Educators' Experiences in an Online Graduate Course. The International Review of Research in Open and Distributed Learning, 14(4): 117-39.

[12] Pope CC, Penney D, Smith TB, 2018, Overtraining and the Complexities of Coaches' Decision- 
Making: Managing Elite Athletes on the Training Cusp. Reflective Practice, 19(2): 145-66.

[13] Greenberger SW, 2020, Creating a Guide for Reflective Practice: Applying Dewey's Reflective Thinking to Document Faculty Scholarly Engagement. Reflective Practice, : 1-15.

[14] Hong YC, Choi I, 2015, Assessing Reflective Thinking in Solving Design Problems: The Development of a Questionnaire. British Journal of Educational Technology, 46(4): 848-63. https://doi.org/10.1111/b jet.12181

[15] Braxton JM, Luckey W, Helland P, 2002, Institutionalizing a Broader View of Scholarship Through Boyer's Four Domains. ASHE-ERIC Higher Education Report. Jossey-Bass Higher and Adult Education Series. Jossey-Bass, San Francisco, CA, 142

[16] Hora MT, Smolarek BB, 2018, Examining Faculty Reflective Practice: A Call for Critical Awareness and Institutional Support. The Journal of Higher Education, 89(4): 553-81. https://doi.org/10.1080/002 21546.2018.1437663 